\title{
Design and Construction of an Automatic Sensor Probe for Soil Moisture Monitoring System
}

\author{
Wisdom Opare* ${ }^{*}$ Peter Otchere \\ Takoradi Technical University, Takoradi- Ghana
}

DOI: $10.36348 /$ sjet.2020.v05i10.002

| Received: 09.08.2020 | Accepted: 17.08.2020 | Published: 05.10.2020

*Corresponding author: Wisdom Opare

\section{Abstract}

Soil moisture monitoring system is the combination of devices that can sense soil moisture, read or store data, and transmit data to a computer, which helps organize, visualize and interpret the soil moisture data. The optimum plant growth is basically dependent on the appropriate water level in the soil. In order to maximize the quality of crops and conserve water resources during irrigation, the soil moisture monitoring device is developed to evaluate and control the amount of water required. In this current project, an op-amp based comparator circuit was used coupled with relay units which controlled the water pumps. Results obtained from the measurement have shown that the system performance is quite reliable and accurate. Field experience has also shown that soil moisture sensors are very useful in diagnosing the changes needed and to fine-tune irrigation practices. The use of these easily available components reduces the manufacturing and maintenance costs. This therefore, makes the proposed system to be an economical, appropriate and a low maintenance solution for applications, especially in rural areas and for small scale agriculturist.

Keywords: Soil moisture monitoring sensor, comparator circuit, irrigation, simulation, field test.

Copyright @ 2020: This is an open-access article distributed under the terms of the Creative Commons Attribution license which permits unrestricted use, distribution, and reproduction in any medium for non-commercial use (NonCommercial, or CC-BY-NC) provided the original author and source are credited.

\section{INTRODUCTION}

Appropriate soil water level is a necessary prerequisite for optimum plant growth. Also, water being an essential element for life sustenance, makes it the necessity to avoid its undue usage. Irrigation is a dominant consumer of water however determining when to irrigate is not an easy task as well. Nickel probes base soil moisture sensor and a response monitoring system was designed and developed to determine the soil moisture. In order to increase the quality of crops, conserve water resources, save energy and decrease fertilizer supplies the moisture content is evaluated to know the amount of water to supply[1-3].

Usually this decision is based on past experiences thus weather forecast information (crop evapo-transpiration data) or soil-related measurements. Past experiences are probabilistic and are often not adjusted for annual changes in weather. Irrigation scheduling based on crop evapo-transpiration can be difficult. This crop evaporation can make scheduling using weather based information uncertain. Because of the shortcomings of these methods, soil-based irrigation scheduling is the preferred technique. Irrigation management by soil moisture measurement reduces the amount of water applied to a crop and reduces excess water, while maintaining soil moisture that is ideal for crop production [4]. Generally, in soil-based measurements, the soil moisture content is monitored. And to achieve this, there are different methods that can be applied. These methods include Feel and Appearance method (using shovel or soil auger), and Meters and Sensors. The Feel and Appearance method is subjective and requires experienced monitoring whilst the latter has sophisticated devices like sensors measuring some physical property that is related with soil moisture. Also, some portable sensing tools are pushed into the soil directly or into an access tube planted in the soil for measurement. Other systems rely on buried sensors that are wired to a fixed meter for it measurement. Being an automated process this provides accurate results with high efficient.

Over the years, automated irrigation systems have been implemented to check the flaws of the manually operated irrigation systems. Most of the existing systems employ micro-processor based systems in their operation. Even though these systems offer several technological advantages, they are very expensive, bulky and difficult to maintain. The current project is to employ modern automated processes for controlling and monitoring the moisture content in the 
Wisdom Opare \& Peter Otchere., Saudi J Eng Technol, October, 2020; 5(10): 351-360

soil so as to enhance plants growth and increase productivity. Furthermore, it makes the proposed system to be economical, appropriate and a low maintenance solution for applications especially in rural areas and for small scale agriculturists. This current study offers a simple, yet affordable soil moisture monitoring system which helps to correct these defects basically aimed to cater for the needs of technologically ignorant rural farmers, check the dryness level of their soil sample and to utilize the existed sensors in a modern way instead of commercially used ones. Several works have been conducted on the soil monitoring system. A recommendation was made by Banerjee and Singhal [5] on the relative humidity and temperature of a soil using microcontroller. Microclimatic parameters were proposed by Dondapati and Rajulu to monitor the cultivation of specific plant species without human involvement [6].

\section{LITERATURE SURVEY}

The necessity for small and large scale farmers to effectively and efficiently monitor the moisture content in the soil has been recognized for centuries. The earliest solution to this problem consists of two methods. These were direct method and indirect method.

The Direct Method (gravimetric measurement of soil water content). The Gravimetric method is the process of producing and weighing a compound or element which is in a pure form as possible after some form of chemical treatment has been carried out on the substances to examined [7]. Figure 1 below is the image of the gravimetric method.

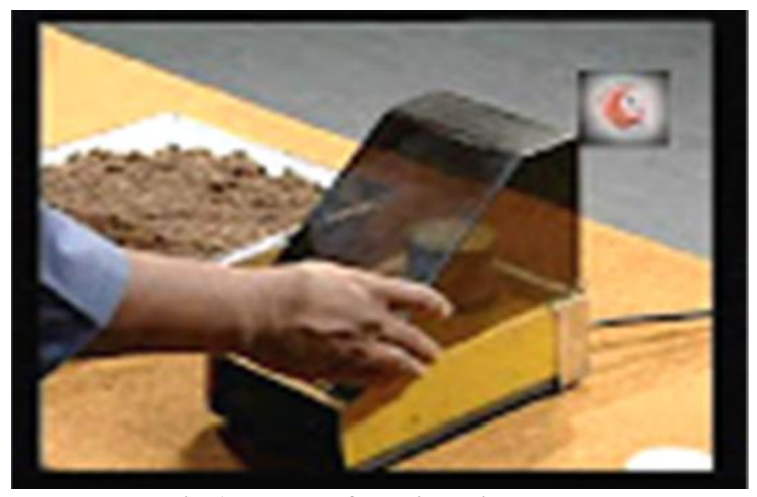

Fig-1: Image of gravimetric method

To achieve this, soil samples of about $50 \mathrm{~g}$ are removed from the field with the best available tools (shovels, spiral hand augers, bucket augers, perhaps power-driven coring tubes), disturbing the sample soil structure as little as possible[8]. The soil sample should be placed immediately in a leak-proof, seamless, preweighed and identified container. As the samples will be placed in an oven, the container should be able to withstand high temperatures without melting or losing significant mass. The samples and container are weighed in the laboratory both before and after drying.
The water mass (or weight) is difference between the weights of the wet and oven dry samples. The gravimetric analysis has the advantage of been accurate and precise when using modern analytical balance. Also the sources of error are readily checked since the filtrates are been tested for completeness of precipitation. It is an absolute method; since it involves direct measurement without any form of calibration required. However, the limitations on the gravimetric analysis are that it requires meticulous time consuming, also it usually provides the analysis of a single element or a limited group of elements at a time. Furthermore, methods are often convoluted and a slight mis-step in a procedure can often mean disaster for the analysis (colloid formation in precipitation gravimetry, for example).

\section{INDIRECT METHOD}

Indirect methods of measuring soil water are helpful as they allow information to be collected at the same location for many observations without disturbing the soil water system. Moreover, most indirect methods determine the volumetric soil water content without any need for soil density determination. A typical example is the radiological method.

The radioactive method is based on the principle of measuring the slowing of neutrons emitted into the soil from a fast-neutron source. The energy loss is much greater in neutron collisions with atoms of low atomic weight and is proportional to the number of such atoms present in the soil [9]. Figure 2 displays the image of the radiological method.

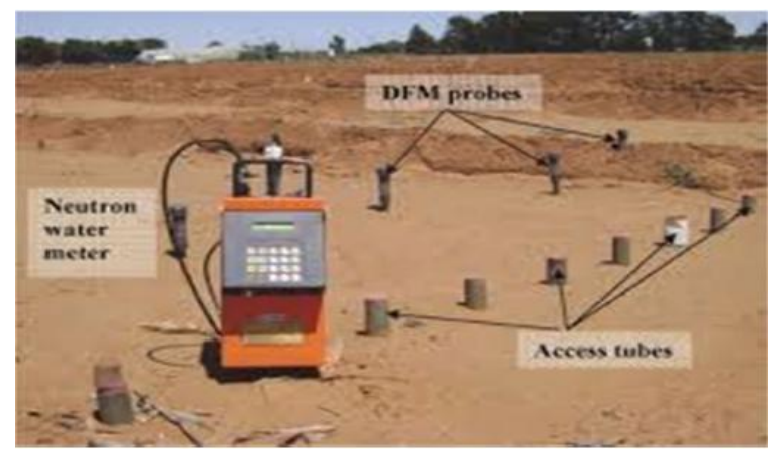

Fig-2: Image of a radiological method

The radioactive method indicates the amount of water per unit volume of soil. The dry density of the soil must be determined if moisture content in percent by weight is desired. The U.S. Corps of Engineers (G, $1955 b$ ) stated that the soil volume measured by this method is bulb shaped and has a radius of 6 to 15 inches, according to the moisture content and density of the soil. The advantages of the radiological method are as follows it is robust and accurate $\left( \pm 0.005 \mathrm{ft}^{3}\right)$, It is not affected by salinity or air gaps. Furthermore, one probe allows for measuring at different soil depths. However, it has limitations of taking relatively long time for each reading, readings close to the soil surface are difficult, 
not accurate and also requires soil-specific calibration which is heavy and comes with a cumbersome instrument as well. Furthermore, it is expensive to buy and the manual readings cannot be automated due to the hazard associated with it.

\section{Soil moisture sensors}

All the previously discussed methods had some limitations which lead to the invention of soil moisture sensors. The soil moisture sensor (SMS) is a sensor connected to an irrigation system controller that measures soil moisture content in the active root zone before each scheduled irrigation event and by passes the cycle if soil moisture is above a user-defined set point [10].

Figure 3 displays the major types of soil moisture sensors namely; resistive sensor, neutron sensor and time domain reflectometry.

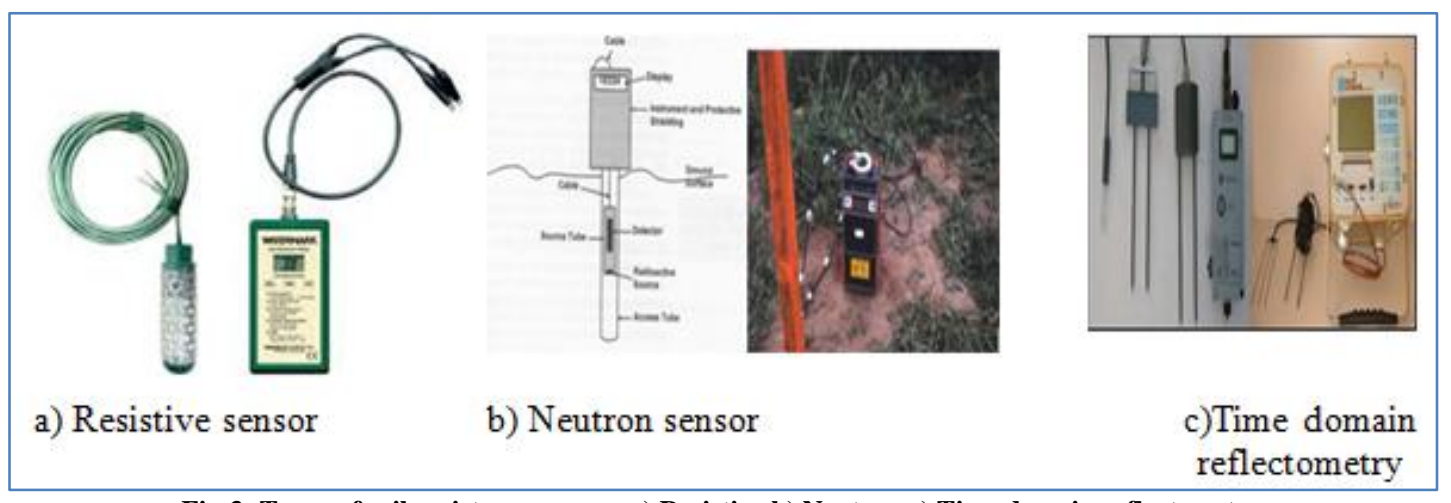

Fig-3: Types of soil moisture sensors: a) Resistive b) Neutron c) Time domain reflectometry

\section{Resistive Sensor}

A resistive sensor constitutes an electrochemical cell with a saturated solution of calcium sulphate as electrolyte. The resistance between the block-embedded electrodes is determined by applying a small AC voltage (to prevent block polarization) using a Wheatstone bridge. Since changes to the soil electrical conductivity would affect readings, gypsum is used as a buffer against soil salinity changes (up to a certain level). The inherent problem is that the block dissolves and degrades over time (especially in saline soils) losing its calibration properties. It is recommended that the block pore size distribution match the soil texture being used [11].

The electrical resistance between electrodes embedded in a porous medium (block) is proportional to its water content, which is related to the soil water matric potential of the surrounding soil. Electrical resistance reduces as the soil, hence the block dries. It has the merits of been suited to regulated deficit irrigation, it is also simple and inexpensive with no maintenance needed. It has the limitations of been very slow in it reaction time. Also it does not work well in sandy soils, where water drains more quickly than the instrument can equilibrate. Furthermore, it is not suitable for swelling soils and has inaccurate readings due to the block hysteresis (i.e., at a fixed soil water potential, the sensor can display different resistance when wetting than when drying).

\section{Neutron Sensor}

Neutron soil moisture sensors (neutron probe) use radioactive material for measuring soil moisture. They contain an electronic gauge, a connecting cable, and a source tube containing both nuclear source and detector tube. The source tube is lowered into the tube to the desired depths of measurement whiles the access tube is installed in the ground [11]. Fast neutrons are emitted from a decaying radioactive source $\left({ }^{241} \mathrm{Am} /{ }^{9} \mathrm{Be}\right)$ and when they collide with particles having the same mass as a neutron (i.e., protons, $\mathrm{H}^{+}$), they slow down dramatically, building a "cloud" of "thermalized"'(slowed-down) neutrons. Since water is the main source of hydrogen in most soils, the density of slowed-down neutrons formed around the probe is nearly proportional to the volume fraction of water present in the soil. It has the merits of not affected by salinity or air gaps, also it is inexpensive per location (i.e., a large number of measurements can be made at different points with the same instrument). Furthermore, one probe allows for measuring at different soil depths. However, it has the limitation of requiring soil-specific calibration and it is also manual readings.

\section{Time-Domain Reflectometry (TDR) Sensors}

Time domain reflectometry probes measure soil moisture directly using reflected electrical signals. A TDR instrument requires a device capable of producing a series of precisely timed electrical pulses with a wide range of high frequencies used by different devices (e.g., 0.02-3GHz), which travel along a TL that is built with a coaxial cable and a probe. This high frequency provides a response less dependent on soil specific properties like texture, salinity or temperature. The TDR probe usually consists of $2-3$ parallel metal rods that are inserted into the soil acting as waveguides in a similar way as an antenna used for television reception. At the same time, the TDR instrument uses a device for measuring and digitizing the energy (voltage) 
level of the TL (Transmission Line) at intervals down to around 100 picoseconds. When the electromagnetic pulse traveling along the TL finds a discontinuity (i.e., probe-wave guides surrounded by soil) part of the pulse is reflected. This produces a change in the energy level of the TL. Thereby the travel time $(t)$ is determined by analyzing the digitized energy levels [12]. The soil bulk dielectric constant $\left(\mathrm{Ka}_{b}\right)$ is determined by measuring the time it takes for an electromagnetic pulse (wave) to propagate along a transmission line (TL) that is surrounded by the soil.

Since the propagation velocity $(v)$ is a function of $\mathrm{Ka}_{b}$, the latter is therefore proportional to the square of the transit time ( $t$, in seconds) down and back along the TL (Transmission Line):

$\mathrm{Ka}_{b}=(c / v)^{2}=((c . t) /(2 . L))^{2}(2)$
Where $c$ is the velocity of electromagnetic waves in a vacuum $\left(3 \cdot 10^{8} \mathrm{~m} / \mathrm{s}\right.$ or $\left.186,282 \mathrm{mile} / \mathrm{s}\right)$ and

$L$ is the length of the TL embedded in the soil (in $/ \mathrm{m} /$ or $\mathrm{ft}$ ). It has the advantages of having wide variety of probe configurations with no requirement of soil specific-calibration.it is relatively insensitive to normal salinity levels. However, it has the limitations of been relatively expensive equipment due to complex electronics. It also requires soil-specific calibration for soils having large amounts of bound water (i.e., those with high organic matter content, volcanic soils, etc.).

\section{Soil moisture monitoring system}

A soil moisture monitoring system is a combination of devices that can perform one or more of the following functions: sense soil moisture, read/store data, and transmit data to a computer, which helps organize, visualize and interpret the soil moisture data.

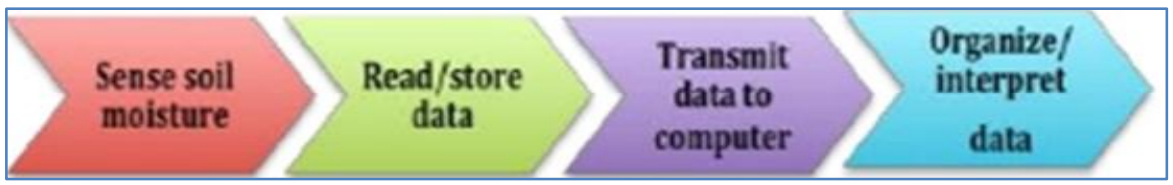

Fig-4: The functions of the soil moisture monitoring system

This system can, therefore, be divided into the following five components, namely: the soil moisture sensing probe, the power supply, the data collection device, the data transmitter, and base station.

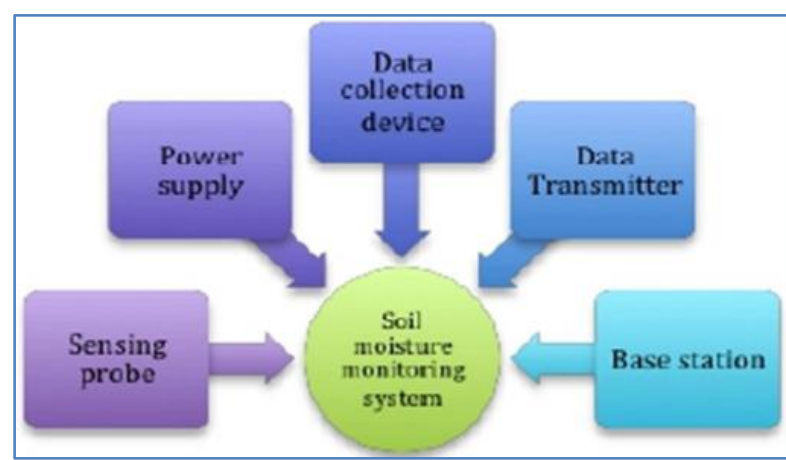

Fig-5: Components of the soil moisture monitoring system

\section{Soil Moisture Sensing Probe}

The soil moisture sensing probe or soil moisture sensor is a device that measures or estimates how much water the soil contains at a given depth and time. The soil moisture probe/sensor does not measure soil moisture directly, but usually derives soil moisture indirectly by measuring other soil properties that depend on soil moisture, such as soil water tension or the ability of soil to conduct or store electricity. There are great varieties of soil moisture probes/sensors on the market today. They range from single soil moisture sensors (Figure 6) that are buried in the ground at the required depth, to soil moisture probes with multiple sensors at different depths, which are installed via an access tube. Probe selection depends on the crop, cost, preference, availability, ease of installation, etc. [12].

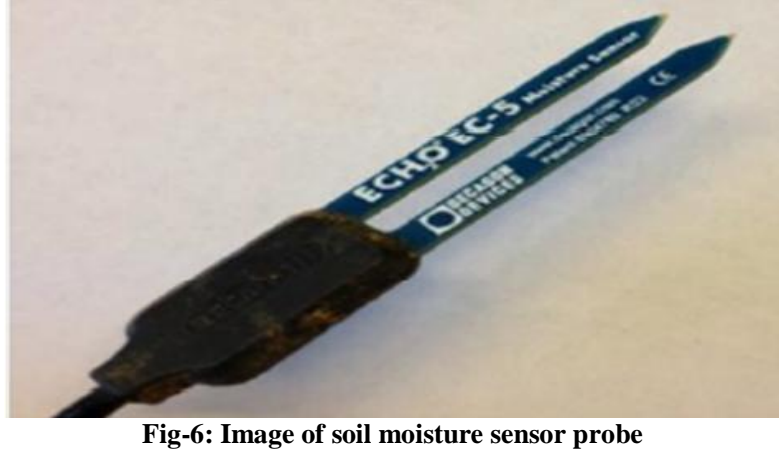

\section{Power Supply}

Since most current soil moisture monitoring systems rely on electronics, a reliable source of electricity is required. Most systems have been designed to operate in remote locations where AC electricity is not available. Therefore, they usually operate with DC power supplied by batteries. Some systems can operate for months using small AA batteries, but others need more power and rely on larger batteries that are recharged with solar panels.

\section{Data Collection Device}

Although some sensors like tension meters have a manual readout to directly read the soil moisture (tension), nowadays most soil moisture probes produce an electronic signal (such as resistance or voltage) that changes with soil moisture, which cannot be seen directly. Therefore, some kind of data collection device is needed to obtain the electrical output from the sensor (s) and convert it to soil moisture or some other unit that is meaningful to the user. The sensor's data can be collected either manually or automatically. With the 
manual data collection, portable readouts are usually employed however the user has to go to the field and connect the portable readout to the soil moisture probe installed in the field [13].

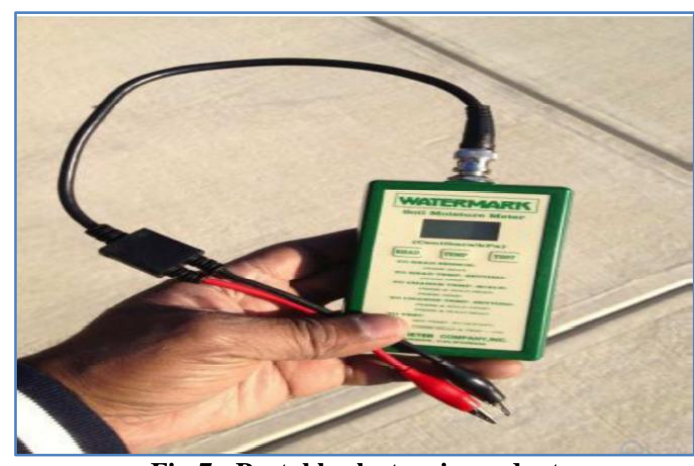

Fig-7: Portable electronic readout

\section{The existing soil moisture monitoring system}

In recent times, new technology based on automated systems have been invented, as they allow information to be collected at high frequency with less labor requirements. Bulk of the existing systems employ micro-processor based systems which offer several technological advantages, but are unaffordable, bulky and difficult to maintain making it difficult for most small and large farmers to increase their production capacity. These flaws in turn affect the nation, leaving human and livestock in the state of hunger. Figure 8 shows the image of how complex and expensive the existing systems are.

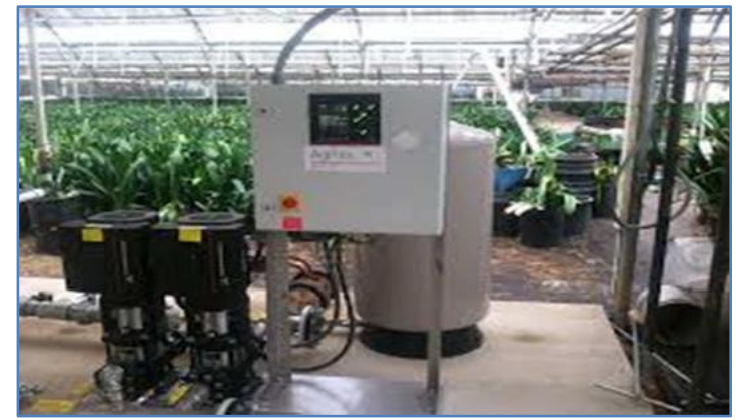

Fig-8: Image of an automated soil moisture monitoring system

\section{The proposed soil moisture monitoring system}

Due to these drawbacks in the existing systems, the current study deals with the design and construction of an automated soil moisture monitoring system which is simple in its design and easy to install. This system monitors and indicates the level of soil moisture that is continuously controlled in order to achieve maximum plant growth and also optimizes the available irrigation resources. Figure 9 shows the image of the constructed system.

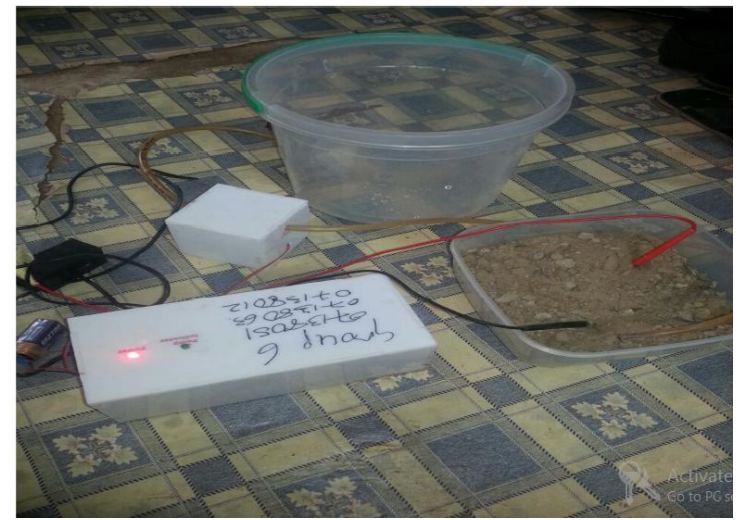

Fig-9: Image of the proposed soil moisture monitoring system

This current study has the merits of it being simple to install, effective and efficient as the existing one. Also, it reduces the undue usage of water for irrigation purposes and reduces the cost involved in purchasing expensive automated soil monitoring systems. Furthermore, it can work on both AC and DC supply.

\section{Description of Components}

This section deals with the components used for constructing the system and their functions.

Table-1: List of Components Used

\begin{tabular}{|l|l|l|l|}
\hline S/No. & Subsystem & Components & Specifications \\
\hline 1. & Sensor & & Resistance block (gypsum) \\
\hline 2. & Comparator & IC LM 358D & \\
\hline 3. & S-R Latch & IC 4011,4049 & \\
\hline 4. & Amplifier & IC 741,potentiometer & \\
\hline 5. & Relay & Relay & 12 volt DC \\
\hline 6. & Indicators & LEDs & Red, Green \\
\hline 7. & Water pump & HJ-1000 model, submersible pump & $220 \mathrm{~V} / 50 \mathrm{~Hz}, 20 \mathrm{~W}$ \\
\hline 8. & Batteries & $6 \mathrm{~F} 22$ & $9 \mathrm{~V}$ \\
\hline
\end{tabular}

Sensor (Gypsum Blocks)

A gypsum block is the type of sensor used in this study which is of importance to moisture content in the soil. An indication of soil moisture levels is provided by electrical resistance blocks. These are a cost-effective tool for effective management of irrigation. They evaluate soil moisture tension by measuring the electrical resistance between the two electrodes emerging out of the block. The blocks absorb 
and release moisture as the soil wets and dries respectively. This electrical resistance is recorded with the help of a portable meter that is attached to the wire leads coming out from the moisture sensors [14]. Instead of using commercially available sensors, effort has been made to build indigenous sensors with the objective to make the study cost effective. With this model, the study employs the use of gypsum for making the sensors. The figure 10 shows the image of gypsum sensor.

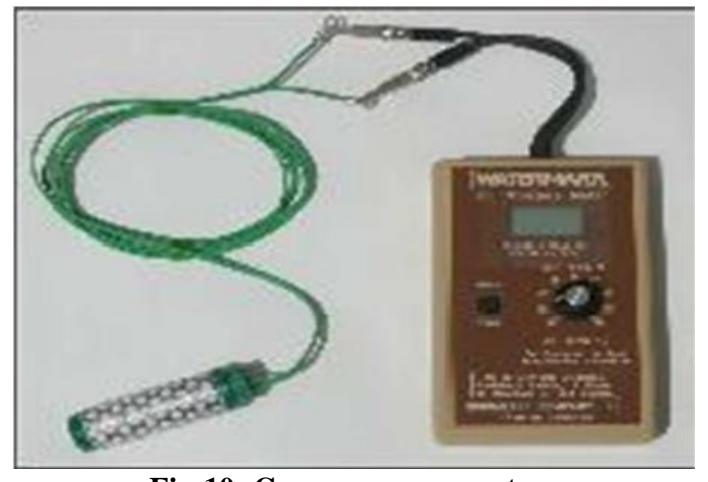

Fig-10: Gypsum sensor system

\section{Comparator}

A comparator is a device for comparing two electrical signals. The comparator device used in this study is IC LM 358 which has two op-amps. Figure 11 shows the image of an IC LM358 comparator.

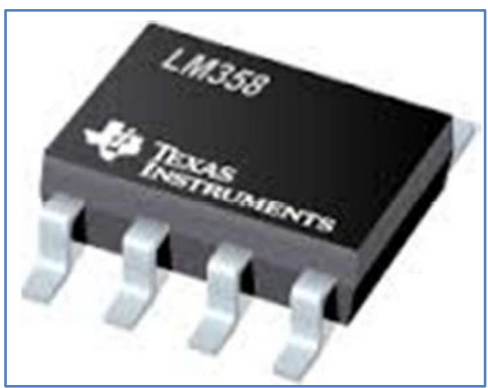

Fig-11: Image of a comparator

In our model, two thresholds were selected: 5 $\mathrm{V}$ for logic high and $3 \mathrm{~V}$ for logic low. These two levels are set at the positive terminal of each op amp. The output of the potential divider is given to the negative terminals of the op amps. The two op amps are arranged such that when the output of the potential divider circuit falls below the Preset value of lower op amp the lower op amp gives logic 0 and the upper op-amp gives logic 1. When the output of potential divider circuit is in between range $(5 \mathrm{~V}$ and $3 \mathrm{~V})$, then both op-amps give logic 1. However, when output of potential divider circuit is above the set value of upper op-amp, then the upper op-amp gives logic 0 and lower op-amp gives logic 1 . The output of the comparator circuit is fed into a SR Latch.

\section{SR Latch}

An SR latch (Set/Reset) is an asynchronous device: it works independently of control signals and relies only on the state of the $\mathrm{S}$ and $\mathrm{R}$ inputs. The SR latch used in this project is IC 4011, 4049. In the image we can see that an SR latch cannot be created with two NOR gates that have a cross-feedback loop. SR latches can also be made from NAND gates, but the inputs are swapped and negated. In this case, it is sometimes called an SR latch.

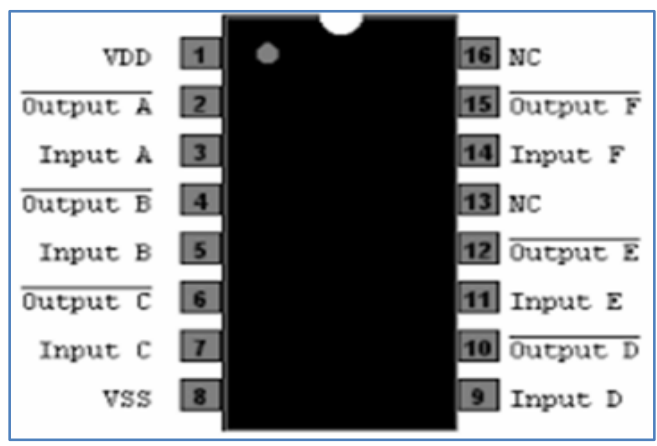

Fig-12: SR latch system

When a high is applied to the Set line of an SR latch, the $Q$ output goes high. The feedback mechanism however, means that the $Q$ output will remain high, even when the $S$ input goes low again. This is how the latch serves as a memory device. Conversely, a high input on the Reset line will drive the $Q$ output low effectively resetting the latch's "memory". When both inputs are low, the latch "latches" - it remains in its previously set or reset state.

\section{Relay}

A relay is an automatic protective and switching device which is capable of sensing abnormal conditions in electrical circuits. These are operated to open or close the load contacts in response to one or more electrical quantities like voltage and current. Finder $12 \mathrm{~V}$ relay is the type of relay used in this study. It is an SPST relay which has a normal current of 10A, a normal voltage of $250 \mathrm{~V}$ and a power supply of $12 \mathrm{~V}$ DC [15]. It has two main output circuit contacts namely Normally Opened (NO) being the first circuit and Normally Closed (NC) being the second circuit. Figure 13 below is the image of a relay.

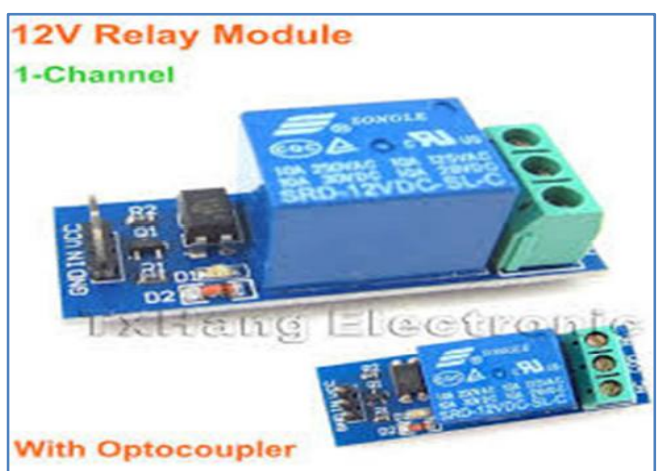

Fig-13: 12V Relay system 


\section{Amplifier of the System}

An amplifier is used to increase the amplitude of a signal waveform, without changing other parameters of the waveform such as frequency or wave shape. They are one of the most commonly used circuits in electronics and perform a variety of functions in a great many electronic systems. In our model, an amplifier with the specification IC 741, was used in constructing the circuit. Figure 14 below is the image of an amplifier. Since the analog output voltage signal from the SR latch is not high enough to drive the relay, hence there is the need for amplification. The signal is amplified using a 741 op-amp and fed to the relay.

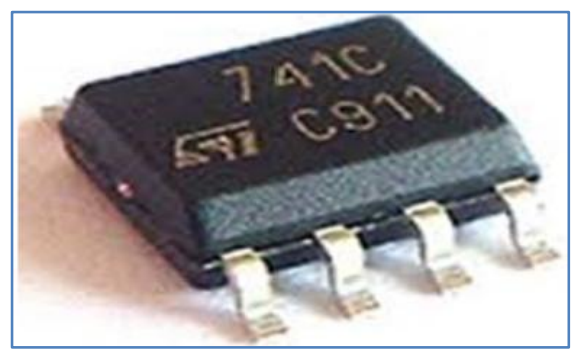

Fig-14: Image of a 741 amplifier

\section{Indicators}

Two LEDs have been used for indication of the various soil conditions.

1. RED for indicating 'ON' condition of water pump

2. GREEN for indicating excess water in the soil.

Table-2: LED and corresponding indication

\begin{tabular}{|l|l|l|}
\hline S/No. & Color of LED that glows & Indication \\
\hline 1 & Green & Excess wet soil \\
\hline 2 & Red & Water pump is ON \\
\hline
\end{tabular}

The Red LED in the above diagram glows, when the water pump is working. This helps to notify the operator that the pump is it operational stage. The water pump is configured to the gypsum block sensor which is planted at a predetermine depth in the soil in other to trigger it, when there is excess water in the soil. In the light of this, when there is excess water in the soil, the sensor triggers the water pump to stop and thus the Red LED goes off, making the Green LED to glow.

\section{Submersible Water Pump}

Submersible pumps are made, as their name implies, to be submersed within a tank, well, or other container. Manufactures' of submersible pumps design many common types of pumps to make them suitable for immersion. The motors of submersible pumps are encased in oil-filled compartments that do not have contact with the substance they are pumping. They have the advantage of being essentially self-priming because they operate below the surface of the media to be pumped. These pumps are normally used for supply of fresh water for drinking, irrigation, and various industrial applications. Figure 15 below is the image of a submersible pump [16].

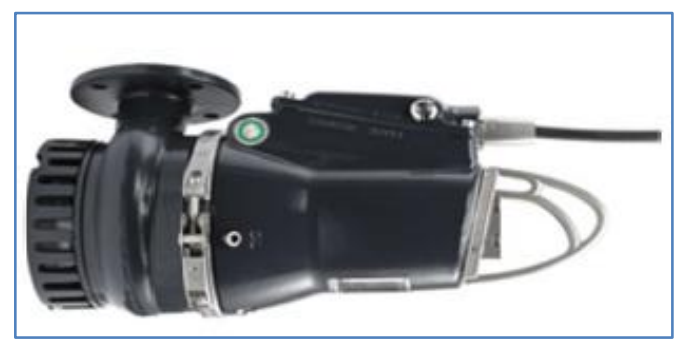

Fig-15: Submersible water pump system

\section{METHODOLOGY System Model}

The block diagram explains the changes in voltage and resistance that occur at different components of the system.

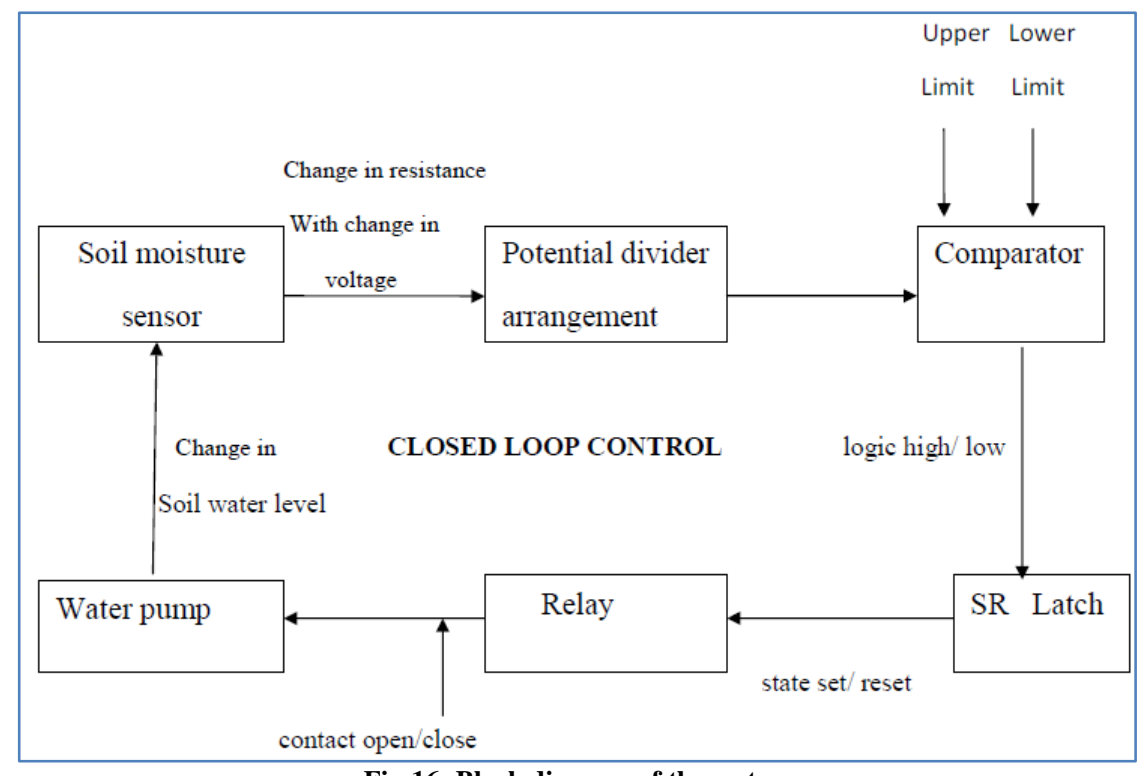

Fig-16: Block diagram of the system 


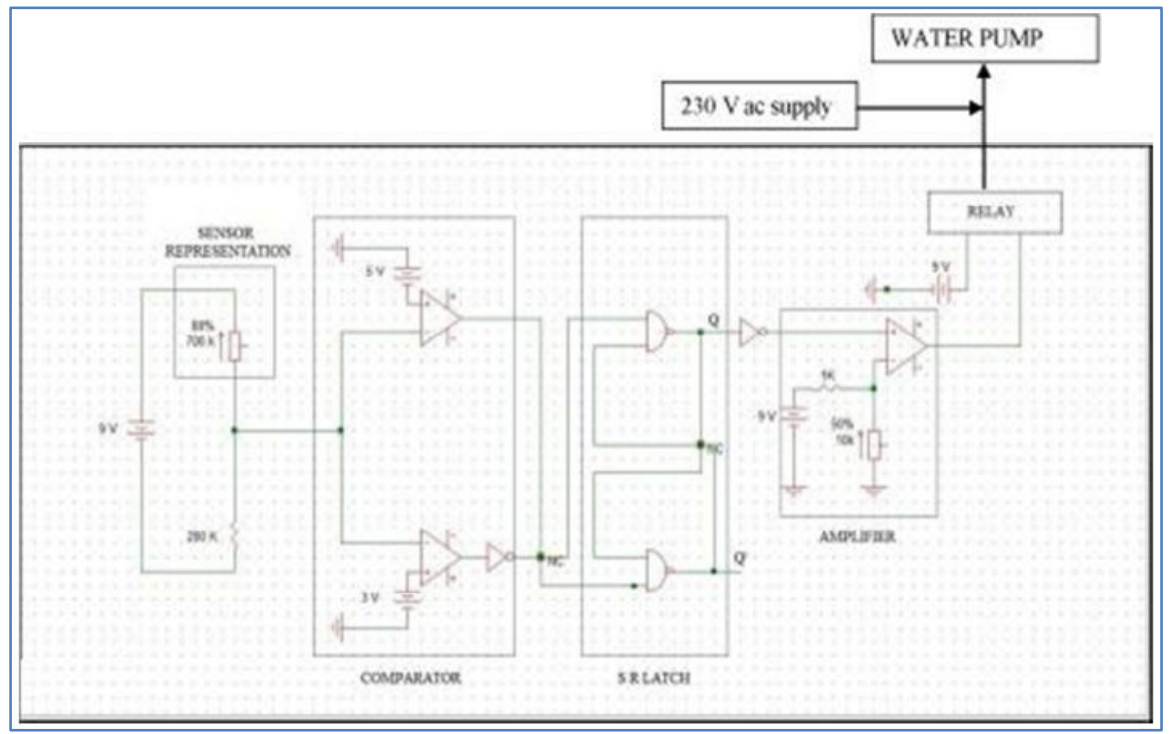

Fig-17: Circuit schematic for hardware model showing the various systems

\section{Setting the Preset Levels}

First, the voltage at minimum and maximum values of moisture can be found out using a sensor and this will give an output in volts. These two voltage levels can be set as higher and lower levels at the op amps. In our model, the $+5 \mathrm{~V}$ and $+3 \mathrm{~V}$ were taken as the upper and lower presets respectively.

\section{Simulation of the circuit using Multi-Sims 11.0}

To test the correctness of the various logics, simulation software was first used to implement the entire system. Also, a variable resistor was used as a representation of the sensor. Varying this resistance as an indication of the varying moisture levels, the schematic was simulated for three conditions: dry, optimum and excess water. The result of the simulation for each condition is shown below. After successful simulation, hardware realization was implemented.

\section{Soldering}

After assembling of the required components output, soldering of the output was done on the breadboard.

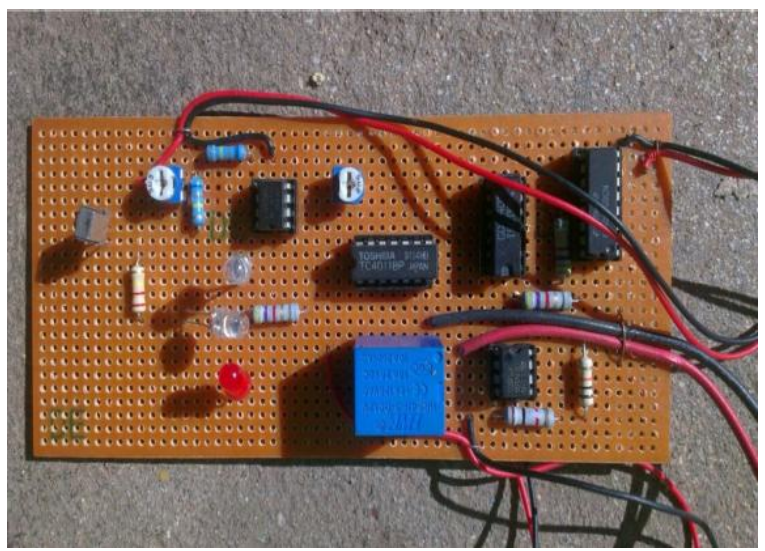

Fig-18: Components on the circuit board
The above circuit shows the components of an IC LM 358D comparator, resistor, potentiometer and several others soldered on a circuit board.

\section{Testing, Validation and Verification}

A set up was done to test for the feasibility of the project. In the setup, the water pump was powered with a $12 \mathrm{v}$ dc supply from a battery source through the 'NO' contact of $12 \mathrm{~V}$ DC relay.

It acts as a switch for the Water pump circuit. Afterwards, the constructed sensor was embedded in the soil below a certain depth to test how it will work with both dry and wet soil. The testing was first done for dry soil then a considerable amount of sufficient water was added to check for wet soil conditions.

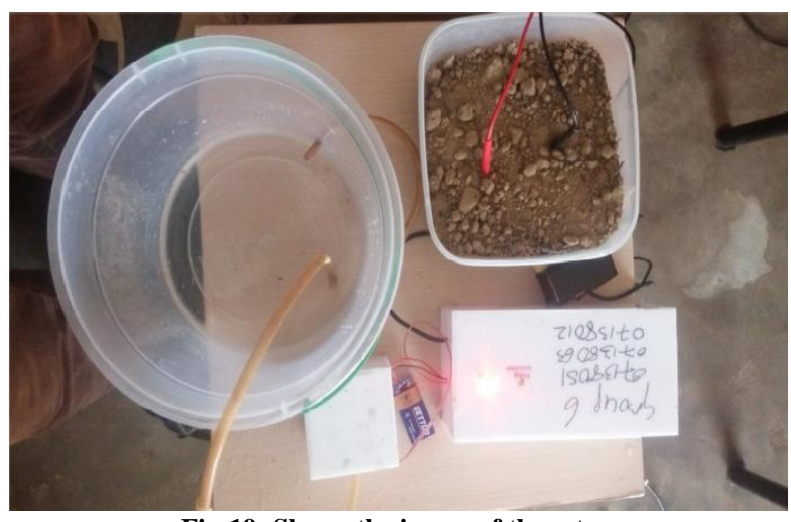

Fig-19: Shows the image of the setup 


\section{Simulation Schematics}

The simulation schematics are shown in figures below;

a) When the sensor senses low moisture

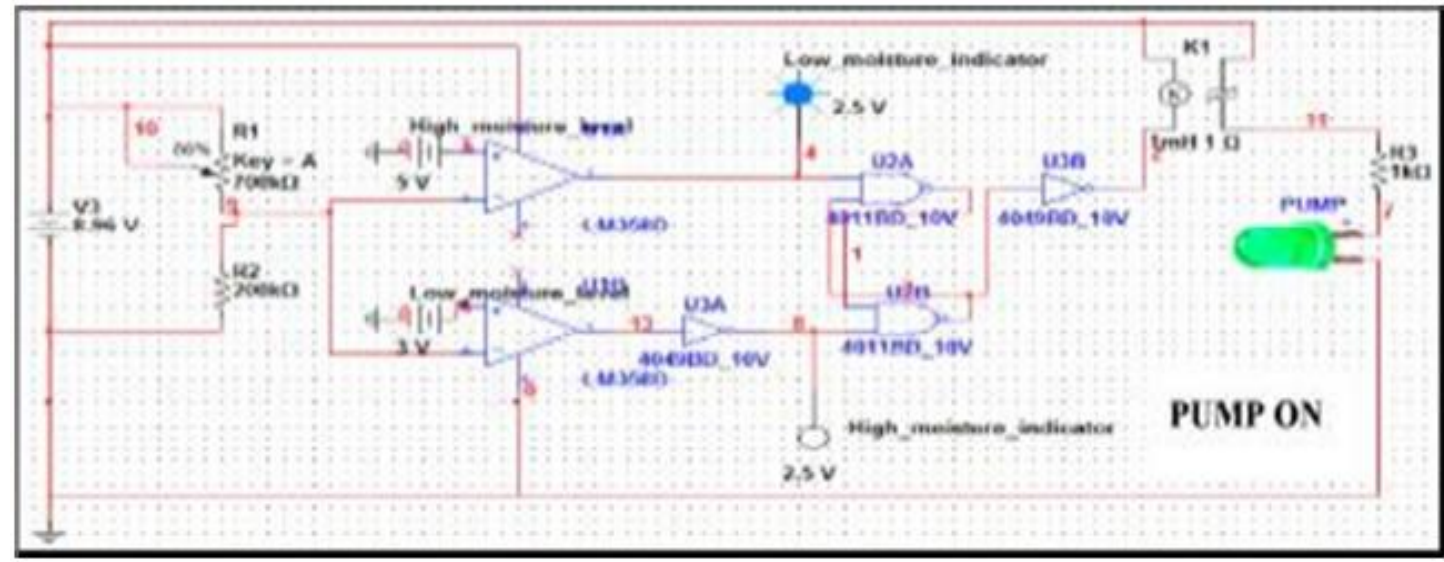

Fig-20: Circuit simulation snaps for dry soil

b) When the sensor senses high moisture

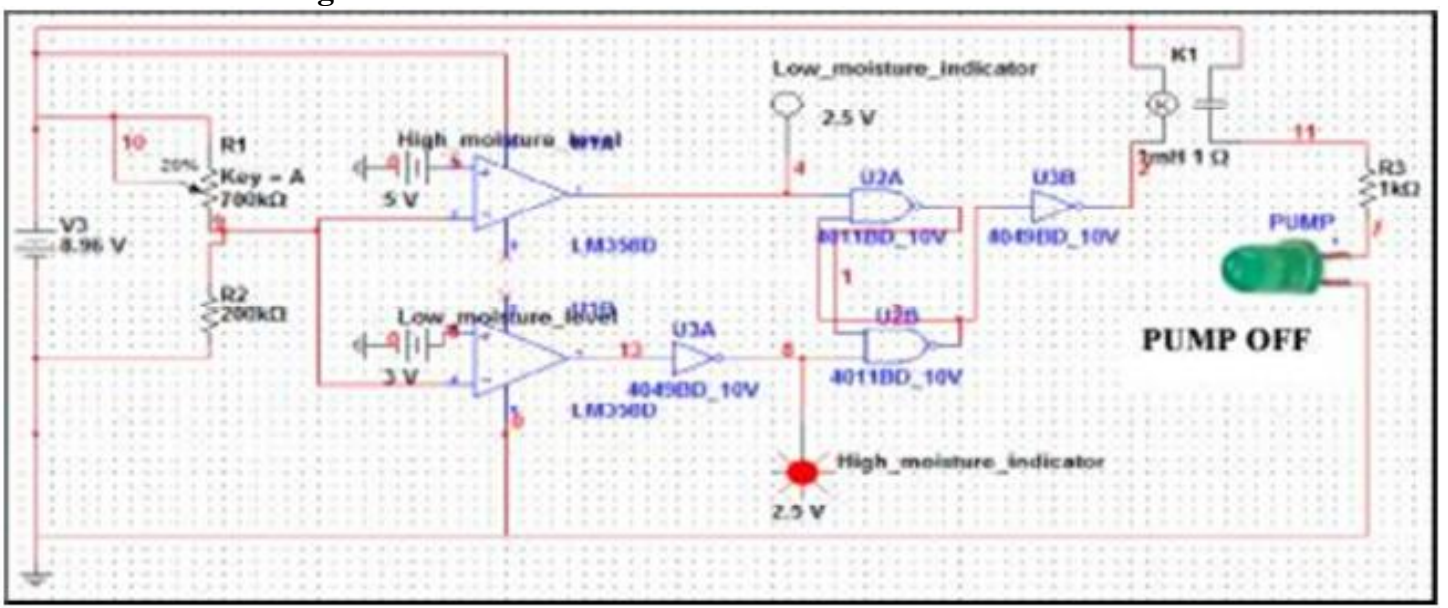

Fig-21: Circuit simulation snap for excess wet soil

\section{RESULTS AND DISCUSSION}

After using a systematic approach for measuring and controlling the moisture level in the soil, the results obtained show that the system performance is quite reliable and accurate. Experiment from the field has shown that soil moisture sensors are very useful in diagnosing the changes needed and to finetune irrigation practices. Soil moisture monitoring system has undoubtedly proven to be easy to maintain, flexible and low cost solution as compared to the existing system. It can therefore, be concluded that this system eliminates the drawbacks of the existing systems by providing an effective and efficient soil moisture monitoring system which will be beneficial to small and large scale farmers.

\section{Simulation Results Using Multi Sims}

By varying the resistance $(700 \mathrm{k} \mathrm{Q})$ in the potential divider circuit as a representation for the dry/wet condition of the sample soil, the circuit was tested and the results are tabulated below.

Table-3: Simulation Results of Wet or Dry Condition of Soil Sample.

\begin{tabular}{|l|l|l|l|}
\hline S/No. & Soil Moisture level & $\begin{array}{l}\text { Output of the sensor } \\
\text { circuit (in volt) }\end{array}$ & $\begin{array}{l}\text { Output of the main pump } \\
\text { controlling circuit(in volt) }\end{array}$ \\
\hline 1. & Below lower level & 2.375 & 0.0 \\
\hline 2. & Increasing but below higher level & 3.262 & 0.0 \\
\hline 3. & More than higher level & 5.265 & 10.0 \\
\hline 4. & $\begin{array}{l}\text { Decreasing but higher than lower } \\
\text { level }\end{array}$ & 4.372 & 10.0 \\
\hline
\end{tabular}

The table above explains the outcome after varying the resistance for both dry and wet soil samples. 
Wisdom Opare \& Peter Otchere., Saudi J Eng Technol, October, 2020; 5(10): 351-360

Observations after Hardware Design

By varying the dry/wet condition of the sample soil, the circuit was tested and the results are tabulated below:

Table-4: Result of the test for dry and wet soil.

\begin{tabular}{|l|l|l|l|}
\hline Voltage from sensor output & Indication & Color of LED that glows & Action \\
\hline Less than 3.06v & Dry Soil & Red & Water pump ON \\
\hline Greater than $4.53 \mathrm{v}$ & Excess wet soil & Green & Water pump OFF \\
\hline
\end{tabular}

The Red LED in the above diagram glows, indicating that the pump is on when the moisture content in the soil is below its predetermine level. The green LED, on the other hand, glows when the soil moisture content exceeds its saturation point.

\section{CONCLUSIONS}

This project uses a simple and reliable electrical resistance block (sensor) for monitoring and indicating the moisture levels in the soil. It is connected to the water pump to trigger it to irrigate the farm land as and when the need arises. The resistance block achieves this aim by evaluating the electrical resistance between the two electrodes when immersed in the soil. It also absorbs and releases moisture as the soil wets and dries respectively. This allows the farm land to be automatically monitored and irrigated.

A methodological approach has been followed in designing the op-amp based system for measurement and control of the plant growth parameter, i.e. soil moisture. The results obtained from the measurement have shown that the system performance is quite reliable and accurate. Field experience has also shown that soil moisture sensors are very useful in diagnosing the changes needed and to fine-tune irrigation practices. Moreover, relatively minor regulations in irrigation practices can pay large dividends in terms of increased yields or water savings. Furthermore, the key to proper irrigation management using soil moisture sensors is regular monitoring of the sensors to track the soil moisture level, and provide irrigation when the readings are in the determined range for the particular soil type. Thus, this system eliminates the drawbacks of the existing set-ups mentioned in the previous section.

\section{REFERENCES}

1. Feng, Z. (2011, April). Research on water-saving irrigation automatic control system based on internet of things. In 2011 International Conference on Electric Information and Control Engineering (pp. 2541-2544). IEEE.

2. Yao, Z., Lou, G., Zeng, X., \& Zhao, Q. (2010, June). Research and development precision irrigation control system in agricultural. In 2010 International Conference on Computer and Communication Technologies in Agriculture Engineering (Vol. 3, pp. 117-120). IEEE.

3. Rangan, K., \& Vigneswaran, T. (2010, November). An embedded systems approach to monitor green house. In Recent Advances in Space Technology
Services and Climate Change 2010 (RSTS \& CC2010) (pp. 61-65). IEEE.

4. Hanson, B., Orloff, S., \& Peters, D. (2000). Monitoring soil moisture helps refine irrigation management. California Agriculture, 54(3), 38-42.

5. Banerjee, G. K., \& Singhal, R. (2010, December). Microcontroller based polyhouse automation controller. In 2010 International Symposium on Electronic System Design (pp. 158-162). IEEE.

6. Dondapati, P. P., \& Rajulu, K. G. (2012). An Automated Multi Sensored Green House Management. International Journal of Technological Exploration and Learning (IJTEL), 1(1), 21-24.

7. Reynolds, S. G. (1970). The gravimetric method of soil moisture determination Part III An examination of factors influencing soil moisture variability. Journal of Hydrology, 11(3), 288-300.

8. Dirksen, C. (1999). Soil Physics Measurements. CatenaVerlag, Reiskirchen, Germany, pp 154.

9. Goldberg, I., Trescony, L. J., Campbell, J. S., \& Whyte, G. J. (1954). Measurement of moisture content and density of soil masses using radioactivity methods. Clays and Clay Minerals, 3(1), 516-548.

10. Street and Highway Conf. (1954). 6th Ann. Mtg., Berkeley, Proc, 136-147

11. Aroca, R. V., Hernandes, A. C., Magalhães, D. V., Becker, M., Vaz, C. M. P., \& Calbo, A. G. (2018). Calibration of passive UHF RFID tags using neural networks to measure soil moisture. Journal of Sensors, 2018.

12. Nicholas, P. (Ed.). (2004). Soil, irrigation and nutrition (No. 2). South Australian Research and Development Institute.

13. Zotarelli, L., Dukes, M. D., Romero, C. C., Migliaccio, K. W., \& Morgan, K. T. (2010). AE459, one of a series of the Agricultural and Biological Engineering Department, UF/IFAS Extension. Original publication date February.

14. Johnson, V. G., Graham, D. L., \& Reidel, S. P. (1993). Methane in Columbia River Basalt aquifers: Isotopic and geohydrologic evidence for a deep coal-bed gas source in the Columbia Basin, Washington. AAPG Bulletin, 77(7), 1192-1207.

15. Elberbaum, D. (2016). U.S. Patent No. 9,281,147. Washington, DC: U.S. Patent and Trademark Office.

16. He, W. H. (2010). U.S. Patent Application No. $12 / 579,917$. 